\title{
Reactivity of uranium and ferrous iron with natural iron oxyhydroxides
}

\author{
Authors: Brandy D. Stewart, A. Cristina Cismasu, \\ Kenneth H. Williams, Brent M. Peyton, \& Peter S. \\ Nico
}

NOTICE: This document is the unedited author's version of a Submitted Work that was subsequently accepted for publication in Environmental Science and Technology, copyright (C) American Chemical Society after peer review. To access the final edited and published work, see http://dx.doi.org/10.1021/acs.est.5b02645.

Stewart BD, Cismasu AC, Williams KH, Peyton BM, Nico PS, "Reactivity of uranium and ferrous iron with natural iron oxyhydroxides," Environmental Science and Technology 2015 49(17): 10357-10365. 


\title{
Reactivity of Uranium and Ferrous Iron with Natural Iron Oxyhydroxides
}

\author{
Brandy D. Stewart, ${ }_{+}^{\dagger}$ A. Cristina Cismasu, Kenneth H. Williams, ${ }^{+}$Brent M. Peyton, ${ }^{\dagger}$ \\ and Peter S. Nico*,
}

\begin{abstract}
${ }^{\dagger}$ Chemical and Biological Engineering, Montana State University, Bozeman, Montana 59717, United
States ${ }^{*}$ awrence Berkeley National Laboratory, Earth Sciences Division, Berkeley, California

94720, United States

ABSTRACT: Determining key reaction pathways involving uranium and iron oxyhydroxides under oxic and anoxic conditions is essential for understanding uranium mobility as well as other iron oxyhydroxide mediated processes, particularly near redox boundaries where redox conditions change rapidly in time and space. Here we examine the reactivity of a ferrihydrite-rich sediment from a surface seep adjacent to a redox boundary at the Rifle, Colorado field site. Iron(II) -sediment incubation experiments indicate that the natural ferrihydrite fraction of the sediment is not susceptible to reductive transformation under conditions that trigger significant mineralogical transformations of synthetic ferrihydrite. No measurable $\mathrm{Fe}$ (II)-promoted transformation was observed when the Rifle sediment was exposed to $30 \mathrm{mM}$ Fe(II) for up to 2 weeks. Incubation of the Rifle sediment with $3 \mathrm{mM} \mathrm{Fe}(\mathrm{II})$ and $0.2 \mathrm{mM} \mathrm{U}(\mathrm{VI})$ for 15 days shows no measurable incorporation of $U(V I)$ into the mineral structure or reduction of $U(V I)$ to $U(I V)$. Results indicate a significantly decreased reactivity of naturally occurring $\mathrm{Fe}$ oxyhydroxides as compared to synthetic minerals, likely due to the association of impurities (e.g., Si, organic matter), with implications for the mobility and bioavailability of uranium and other associated species in field environments.
\end{abstract}

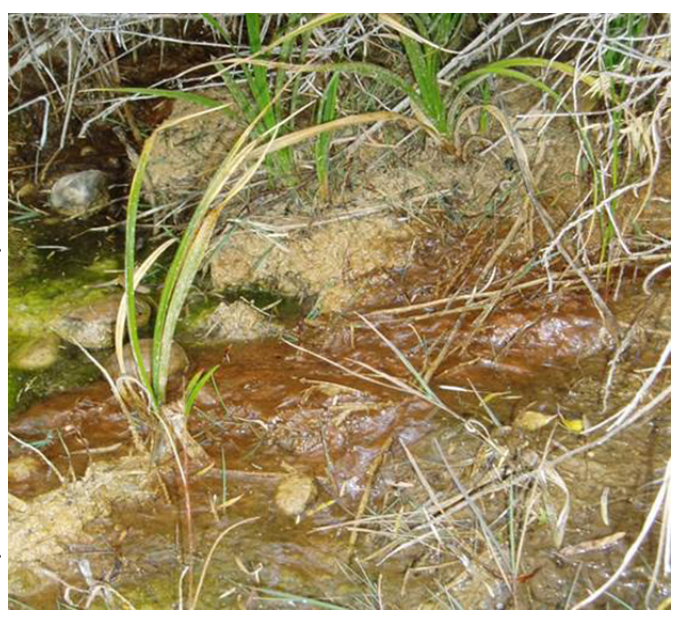

\section{INTRODUCTION:}

Mining and nuclear enrichment activities throughout the last century have created a legacy of uranium and cocontaminants in the environment. Within the U.S. alone uranium has been located in over 3000 inactive waste disposal areas within the Department of Energy (DOE) Complex, ${ }^{1}$ in addition to more than 20 inactive uranium mill tailing sites in 10 states. $^{2}$ In many cases, uranium, a contaminant of concern due to its toxic effects and radioactivity, has migrated from waste disposal sites to surrounding soils, sediments, and waters where its fate is

often controlled by redox and sorption processes, and in particular the proportion of U(VI) to U(IV) ${ }^{3}$ Understanding the stability and mobility of these U-bearing materials is critical to the DOE remediation effort. In recent years uranium transformation and mobility has been studied extensively at the DOE Old Rifle former mill site near Rifle, CO where uranium was processed from 1942 to 1958. Despite the removal of mill tailings and surface waste between 1992 and 1996, uranium contamination in the underlying sediments and aquifer persists today $^{4}$

Redox fluctuations can promote the dissolution of iron bearing minerals (including iron oxides) and the precipitation of fresh Fe(III) precipitates, influencing the surrounding biogeochemistry. Thompson et al. report that iron oxide crystallinity generally increases during redox fluctuations ${ }^{5}$ and that newly formed oxides may include impurities, such as metals, oxyanions and organic acids. ${ }^{6}$ Additionally, iron oxidation under low dissolved oxygen conditions (i.e., in redox transition areas) can promote formation of both organic Fe(III) complexes and disordered, impure ferrihydrite-organic matter coprecipitates. ${ }^{6-8}$ The reactivity of these fresh precipitates is particularly relevant for the sorption and coprecipitation of other metals and organic matter, and their reactivity and stability in the environment may influence the ultimate fate of these species.

$\mathrm{Fe}$ oxyhydroxides are strong sorbents of uranium due to their high reactivity, ${ }^{9}$ their high surface area $(<50 \mathrm{~m} 2 /$ g) and prevalence in natural systems. Uranium and Fe have been found concomitantly in environmental settings over a vast range of temporal scales. Some studies have observed the association of $\mathrm{U}$ and $\mathrm{Fe}$ on geologic time scales on the order of millions of years. ${ }^{10}$ Uranium has also been found in association with $\mathrm{Fe}$ and phosphate mineral phases at the DOE Oak Ridge, TN nuclear reservation, $11_{12}$ in close association with sediments naturally elevated in organic matter and in mine wastes where associations have formed within the last 75 years. Both $\mathrm{U}$ adsorption to oxide surfaces followed by incorporation, as well as $\mathrm{U}$ and Fe oxyhydroxide coprecipitation have been postulated as potential explanations for $\mathrm{U}-\mathrm{Fe}$ association. ${ }^{14}$ Accordingly in recent years, several studies have observed $U$ incorporation into synthetic Fe oxides under a variety of experimental conditions including during $\mathrm{Fe}(\mathrm{II})$ promoted 
reductive transformation ${ }^{15}$ of $\mathrm{Fe}(\mathrm{III})$ oxyhydroxides. In several of these studies $\mathrm{U}(\mathrm{VI})$ was removed from solution, remained in an oxidized form and was found both adsorbed on and incorporated into the structure of newly formed goethite and magnetite.

Here we provide evidence for the persistence of a natural ferrihydrite-rich material adjacent to the Old Rifle site in the presence of $\mathrm{Fe}(\mathrm{II})$ and $\mathrm{U}(\mathrm{VI})$ in a redox boundary region. Owing to the complexity of natural samples, we examine the compound impact of multiple impurities (trace metals and organic matter, which may be present within the structure or on the surface of the $\mathrm{Fe}$ (III) mineral) on $\mathrm{Fe}(\mathrm{II})$-promoted transformation, as well as the potential for uranium uptake during iron oxyhydroxide transformations induced by $\mathrm{Fe}$ (II). Additionally we evaluate the potential of the natural sediment as an adsorbent for $\mathrm{U}(\mathrm{VI})$ as compared to synthetic ferrihydrite.

\section{MATERIALS AND METHODS}

Chemical Extractions. Field samples were collected aseptically and placed in sterile plastic tubes before being placed on dry ice and expedited to Montana State University where they were stored at $-80{ }^{\circ} \mathrm{C}$ until the time of experiments. Immediately prior to experiments sediments were dried, pieces of debris (primarly rock) were removed, and samples were homogenized by gently crushing with a mortar and pestle. The unreacted sediment was silty clay, very fine, and bright reddish-brown in color.

Chemical extractions were carried out to estimate the total iron bound in $\mathrm{Fe}$ oxyhydroxides, the amount of $\mathrm{Fe}$ bound in poorly crystalline oxyhydroxides, the amount of inorganic impurities (e.g., Si, Al, Mn, etc.), and the amount of organic carbon released. The modified inorganic dithionite extraction developed by Wagai and Mayer ${ }^{16}$ was used to determine total reactive $\mathrm{Fe}$ bound in $\mathrm{Fe}$ oxides; this version of the citratedithionite extraction was chosen since it does not include citrate, and thus allowed us to quantify the organic carbon content of the extract. The extraction procedure consisted of reacting $100 \mathrm{mg}$ of sediment in $30 \mathrm{~mL}$ of a $0.05 \mathrm{M}$ sodium dithionite solution ( $\mathrm{pH} \mathrm{4.4)}$ for $16 \mathrm{~h}$ at room temperature on a rotational shaker. Subsequent to the reaction period, solids were separated by centrifugation ( $40 \mathrm{~min}$ at $35000 \mathrm{~g}$ ) and resuspended in $30 \mathrm{~mL}$ of a $0.5 \mathrm{M} \mathrm{HCl}$ solution at room temperature for an hour to dissolve any Fe that precipitated as acid-volatile sulfides; this second extract was also collected after centrifugation (40 $\mathrm{min}$ at $35000 \mathrm{~g}$ ).

An additional hydroxylamine hydrochloride extraction ${ }^{17}$ was used to estimate the amount of Fe bound in poorly crystalline Fe oxyhydroxides, the amount of trace metal(loids) and organic carbon released. This procedure consisted of reacting $100 \mathrm{mg}$ of sediment in $25 \mathrm{~mL} 0.25 \mathrm{M}$ hydroxylamine hydrochloride $+0.25 \mathrm{M} \mathrm{HCl}$ solution ( $\mathrm{pH} \mathrm{0.8),} \mathrm{for} 1 \mathrm{~h}$ in a water bath at a temperature of $50{ }^{\circ} \mathrm{C}$ under moderate shaking. These suspensions were filtered using a $0.45 \mu \mathrm{m}$ filter prior to ICPMS analysis. The composition of each extract was obtained using a PerkinElmer SCIEX Elan DRC II inductively coupled plasma mass spectrometer. Total organic and inorganic carbon contents in the unreacted sediment and in the hydroxylamine hydrochloride and dithionite extracts were measured using a Shimadzu TOC-VCSH high sensitivity inorganic/organic carbon analyzer, which is also equipped with a SSM-5000A module for solid sample analysis. Finally, a total digestion was performed using ALS Minerals Methods ME-MS81/ICP06 where samples were fused at $1000{ }^{\circ} \mathrm{C}$ in lithium metaborate/ lithium tetraborate flux followed by dissolution in $4 \%$ nitric acid/2\% hydrochloric acid and analysis by ICP-AES/MS.

Incubation Experiments. Three sets of batch experiments were conducted to examine the reactivity of the unreacted sediment toward $\mathrm{Fe}(\mathrm{II})$ and $\mathrm{U}$. The first of these examined the reactivity of the sediment toward $\mathrm{Fe}$ (II). Systems contained 0.5 g unreacted Rifle sediment, $50 \mathrm{~mL}$ PIPES buffered distilleddeionized (DDI) water (10 mM PIPES, $\mathrm{pH} 7)$ and varying concentrations of ferrous sulfate $\left(\mathrm{FeSO}_{4}\right)(3,10$, or $30 \mathrm{mM})$. Solutions were made anoxic $(<0.02 \mathrm{mg} / \mathrm{L})$ by boiling and cooling under a stream of $\mathrm{N}_{2}$ gas and systems were assembled under anoxic conditions in a glovebag (Coy Laboratory Products) with a $\mathrm{N}_{2}$ (90\%): $\mathrm{H}_{2}$ (5\%): $\mathrm{CO}_{2}(5 \%)$ atmosphere. Experiments were deconstructed and aqueous $\mathrm{Fe}(\mathrm{II})$ concentrations measured at the end point of each experiment $(2,8.5$, and 14 weeks) where ca. $1.5,7$, and $18 \mathrm{mM} \mathrm{Fe}$ (II) remained for $3,10,30 \mathrm{mM}$ starting concentrations respectively (irrespective of incubation time).

A second experiment examined the interaction of the sediment and U(VI) (adsorption). A parallel set of experiments were run with synthetic ferrihydrite and $\mathrm{U}(\mathrm{VI})$ for comparison to the Rifle sediment. Ferrihydrite was prepared according to the method described by Brooks et al. ${ }^{18} \mathrm{~A}$ solution of ferric chloride was rapidly titrated with sodium hydroxide over a period of approximately $10 \mathrm{~min}$ until a $\mathrm{pH}$ of 7 was reached. Chloride and sodium were then removed from the ferrihydrite with sequential rinses. Ferrihydrite was then dried and purity of product was confirmed using XRD. Adsorption batch systems contained $0.2 \mathrm{~g}$ of unreacted sediment or ferrihydrite, and 100 $\mathrm{mL}$ PIPES buffered distilled-deionized (DDI) water $(10 \mathrm{mM}$, $\mathrm{pH} 7$ ) with the following components: $1 \mathrm{mM} \mathrm{CaCl}_{2}, 3.8 \mathrm{mM}$ $\mathrm{KHCO}_{3}$, and varying concentrations of uranyl acetate ranging from 0 to $0.15 \mathrm{mM}$. $\mathrm{pH}$ and chemistry remained constant throughout the experiment.

The final batch experiment studied the interaction of the sediment with $\mathrm{U}(\mathrm{VI})$ and $\mathrm{Fe}(\mathrm{II})$ concurrently. Experiments contained unreacted sediment, PIPES buffered distilleddeionized (DDI) water (10 mM, pH 7), $3 \mathrm{mM} \mathrm{CaCl}_{2}, 3$ or $10 \mathrm{mM} \mathrm{FeSO}_{4}$, and $0.2 \mathrm{mM}$ uranyl acetate. Solutions were made anoxic as described above. All experiments were shaken at $85 \mathrm{rpm}$ at $25^{\circ} \mathrm{C}$ outside of the glovebag and were conducted in triplicate. All U(VI) concentrations were measured on a kinetic phosphorescence analyzer (KPA) instrument (Columbus Instruments). Samples were vacuum filtered, rinsed with DDI, dried, and sealed inside Kapton tape prior to XRD and XAS analysis.

XRD Analysis. Micro X-ray diffraction ( $\mu$ XRD) data for the unreacted Rifle sediment and for sediment reacted with 3, 10, and $30 \mathrm{mM} \mathrm{Fe}$ (II) for 8.5 weeks were collected at the Stanford Synchrotron Radiation Lightsource (SSRL) beamline 11-3 at an energy of $12.7 \mathrm{keV}$, which corresponds to a wavelength of $0.9762 \AA$, using a beam spot size of $0.1 \mathrm{~mm}$. A thin sediment powder film was sandwiched in Kapton tape for all measurements. Data were collected on a MAR 3450 detector at a sample-detector distance of $\sim 150 \mathrm{~mm}$. Five frames, each exposed for $250 \mathrm{~s}$ were collected for each sample over different sample areas; data were also collected on a blank sample (Kapton tape), which allowed for subtraction of scatter resulting primarily from the sample mount (background). Calibration of the sample to detector distance was done using a lanthanum hexaboride standard $\left(\mathrm{LaB}_{6}\right)$. Raw data were 
integrated using the software Fit2 $\mathrm{D}^{19}$ and the background (Kapton) subtraction was done using the software XRD-BS.

X-ray Absorption Spectroscopy. Fe K-edge X-ray absorption spectroscopy data for the unreacted and $\mathrm{Fe}(\mathrm{II})$ reacted samples $(3,10$, and $30 \mathrm{mM} \mathrm{Fe}$ (II) for 2 weeks; $3 \mathrm{mM}$ $\mathrm{Fe}(\mathrm{II})$ for 8.5 weeks; $3 \mathrm{mM} \mathrm{Fe}$ (II) for 14 weeks) were collected at room temperature at the Stanford Synchrotron Radiation Lightsource, beamline 11-2, using a Stern-Heald (Lytle) detector and a Si 220 double-crystal monochromator in a phi $=0$ orientation (additional details found in Supporting Information).

Data extraction, processing, least-squares fits and principal component analyses were done using the SixPack software package. ${ }^{20} \mathrm{k}^{3}$-weighted EXAFS $\left(k_{\max }=13 \AA^{-1}\right)$ were used for principal component analysis (PCA) and linear combination fits (LCF) to determine the number, type and proportion of the predominant $\mathrm{Fe}$ phases as a function of reaction with $\mathrm{Fe}(\mathrm{II})$. PCA was carried out initially to constrain the minimum number of components needed to describe the data set by using all six Fe EXAFS spectra of the unreacted and Fe(II)reacted samples. Two major components were found to describe the data set, according to variance values of 0.7 and 0.1 for the first two components, which indicate that one major and one secondary phase explain up to $80 \%$ of variance within the series of spectra. Target transformations were used subsequently to identify mineral phases that constitute probable components in the experimental data set. Ferrihydrite yielded a good fit according to target transformations; smectite also appeared suitable, although a poorer fit was obtained. Target transforms were also carried out against additional reference compounds (goethite, hematite, magnetite, hydroxycarbonate green rust, siderite, pyroxene, hornblende, biotite) but did not provide satisfactory fits, indicating that these phases are likely not abundant in the Rifle sediment.

LCFs were carried out using the Fe-bearing phases identified by PCA and XRD, that is, ferrihydrite and smectite, and fit attempts using other reference spectra were not successful. For all LCFs, component sums were set to 1 , and similar results were obtained without this constraint. Data were allowed to shift in energy during fitting, with maximum obtained shifts of $0.05 \mathrm{eV}$.

$\mathrm{U} \mathrm{L}_{\mathrm{III}}$-edge $\mathrm{X}$-ray absorption spectroscopy data for the unreacted sediment and $\mathrm{U}(\mathrm{VI})-\mathrm{Fe}(\mathrm{II})$ reacted sediments were also collected at Stanford Synchrotron Radiation Lightsource, beamline 11-2 (double crystal Si220 monochromator using a 30-element germanium detector). Energy calibration was monitored using a Y foil. Spectra for a sample of U(VI) adsorbed onto synthetic ferrihydrite were collected under similar experimental conditions for comparison.

\section{RESULTS AND DISCUSSION}

Field Sampling Collection. Samples were collected from a hillside seep located directly to the north and upgradient from the U.S Department of Energy Rifle, CO field site (photograph of field site in Supporting Information). Field measurements showed nondetectable concentrations of $\mathrm{O}_{2}$ in the water at the head of the seep closest to the hillside. This is consistent with low groundwater $\mathrm{O}_{2}$ concentrations present within an alluvial aquifer directly downgradient of the seep. ${ }^{21}$ Within $\sim 1 \mathrm{~m}$ of the seep origin dissolved $\mathrm{O}_{2}$ increased to ca. $10.7 \mathrm{mg} / \mathrm{L}$, while $\mathrm{pH}$ remained constant at 6.9. The detected change from reduced to oxic conditions were supported by dramatic decreases in the concentration of both $\mathrm{Mn}$ and Fe from ca. 790 and ca. 3760 $\mathrm{ug} / \mathrm{L}$ at the head of the seep to 12 and $<10 \mathrm{ug} / \mathrm{L}$, respectively, $\sim 1 \mathrm{~m}$ downgradient indicating oxidative precipitation of these two redox sensitive elements. This was consistent with the appearance of a red, iron-rich precipitate as the water flowed at the surface and became oxygenated. Beyond spring and seep discharge localities encountered globally, the conditions described here are equally characteristic of redox boundaries encountered under a diversity of environmental conditions. These include capillary fringe sediments exposed to variably saturated conditions accompanying fluctuations in groundwater, anoxic aquifer sediments seasonally infiltrated by oxygenated meltwater and precipitation, and hyporheic interfaces between anoxic groundwater and adjoining surface waters. Each of the aforementioned conditions exists at the adjoining Rifle field site, and as such, the results reported here for redox boundaries at circumneutral conditions and the resulting precipitates are deemed representative of the types of materials that could form at such boundaries.

Composition of the Fe-Rich Sediment Fraction. Two chemical extractions were used to evaluate the composition of the $\mathrm{Fe}$ oxyhydroxides in the unreacted sediment. The composition of the poorly crystalline, hydroxylamine-hydrochloride extractable component of the sediment is given in Table 1 along with results of the sodium dithionite extraction,

Table 1. (a) Composition of the Hydroxylamine Hydrochloride Extract (Hydroxylamine $\mathrm{HCl}$ ), Used to Approximate Fe Bound in Poorly Crystalline Phases in the Unreacted Sediment, The Sodium Dithionite Extract ( $\mathrm{Na}$ Dithionite), Which Estimates Total Reactive Fe, and the Total Digestion Extract. (b) Total Inorganic Carbon (TIC) and Total Organic Carbon (TOC) Determined in the Bulk Sediment

\begin{tabular}{|c|c|c|c|c|c|}
\hline \multirow[b]{2}{*}{ (a) } & \multicolumn{2}{|c|}{$\begin{array}{c}\text { hydroxylamine } \mathrm{HCl} \\
(\mathrm{pH} 0.8)\end{array}$} & \multicolumn{2}{|c|}{ Na dithionite ( $\mathrm{pH} 4.4)$} & \multirow[b]{2}{*}{ total digestion } \\
\hline & avg & stdev & avg & stdev & \\
\hline $\mathrm{Si}$ & 4.3 & 0.1 & 5.0 & 0.1 & 102 \\
\hline $\mathrm{Al}$ & 0.56 & 0.01 & 0.62 & 0.01 & 22 \\
\hline $\mathrm{Fe}$ & 43 & 2 & 44 & 1 & 42 \\
\hline $\mathrm{Mn}$ & 0.93 & 0.05 & 1.0 & 0.2 & 2.7 \\
\hline $\mathrm{Mg}$ & 4.3 & 0.3 & 3.51 & 0.09 & 9.0 \\
\hline $\mathrm{Ca}$ & 49 & 5.3 & 49 & 2 & 165 \\
\hline $\mathrm{K}$ & 0.14 & 0.01 & 0.4 & 0.1 & 4.3 \\
\hline $\mathrm{V}$ & 0.123 & 0.004 & 0.129 & 0.005 & 0.148 \\
\hline $\mathrm{Se}$ & 0.0065 & 0.0003 & 0.008 & 0.001 & 0.016 \\
\hline $\mathrm{Ni}$ & 0.008 & 0.003 & 0.0065 & 0.0002 & 0.008 \\
\hline Co & 0.0055 & 0.0002 & 0.0058 & 0.0005 & 0.015 \\
\hline $\mathrm{Cu}$ & 0.009 & 0.001 & 0.0122 & 0.0002 & 0.012 \\
\hline $\mathrm{Zn}$ & 0.0358 & 0.0002 & 0.19 & 0.01 & 0.047 \\
\hline As & 0.062 & 0.002 & 0.0688 & 0.002 & 0.042 \\
\hline $\mathrm{Sr}$ & 0.460 & 0.02 & 0.46 & 0.02 & 1.01 \\
\hline $\mathrm{U}$ & 0.0057 & 0.0003 & 0.0041 & 0.0001 & 0.009 \\
\hline \multirow[t]{4}{*}{$\mathrm{C}_{\text {org }}$} & 15.27 & & 24.78 & & \\
\hline & (b) & & & & \\
\hline & TOC $^{b}$ & & $\%$ & & 3.8 \\
\hline & $\mathrm{TIC}^{b}$ & & $\%$ & & 1.9 \\
\hline
\end{tabular}

$a_{\mathrm{mg} / \mathrm{g}}$ sediment. ${ }^{b_{\text {Thal }}}$ organic and inorganic $\mathrm{C}$ in sediment measured on solid phase. ${ }^{c}$ ALS Minerals Methods ME-MS81/ ICP06: sample fused at $1000{ }^{\circ} \mathrm{C}$ in lithium metaborate/lithium tetraborate flux followed by dissolution in $4 \%$ nitric acid/2\% hydrochloric acid and analysis by ICP-AES/MS. 
which accounts for total reactive iron. Extractions were completed in triplicate and results shown are averages. The results of the two extractions and a total digestion are comparable in terms of $\mathrm{Fe}$ content, 43, 44, $42 \mathrm{mg} / \mathrm{g}$ respectively, suggesting that the vast majority of the $\mathrm{Fe}$ is associated with poorly crystalline phases. Significant calcium (49 $\mathrm{mg} \mathrm{Ca} / \mathrm{g}$ sediment), as well as $\mathrm{Mg}$ and $\mathrm{Si}$ (up to 4 and 5 $\mathrm{mg} / \mathrm{g}$ sediment, respectively), $\mathrm{Al}$ and $\mathrm{Mn}$ (up to 0.6 and $1 \mathrm{mg}$ / g sediment) were also extracted. In both extractions, the $\mathrm{Al}: \mathrm{Fe}$ and $\mathrm{Mn}: \mathrm{Fe}$ molar ratios are $\sim 0.02$, whereas the $\mathrm{Si}: \mathrm{Fe}$ ratio is 10 times larger, $\sim 0.2$. Vanadium and strontium are the most abundant trace impurities, at concentrations of up to 0.13 and $0.46 \mathrm{mg} / \mathrm{g}$, respectively. The total organic carbon (TOC) content in the dry sediment is $\sim 3.8 \%$, and total inorganic $\mathrm{C}$ (TIC) is $\sim 1.9 \%$. Organic C was also measured in the hydroxylamine and the dithionite extracts, and values of 15.3 and $24.8 \mathrm{mg} \mathrm{C} / \mathrm{g}$ were obtained, respectively, which correspond to molar C:Fe ratios of $\sim 1.5$.

Selective dissolution using ammonium oxalate or hydroxylamine hydrochloride solutions is generally used as an indication for the occurrence of ferrihydrite-like $\mathrm{Fe}$ oxyhydroxides in complex natural samples, ${ }^{22}$ and coextracted impurities e.g., Al, $\mathrm{Si}, \mathrm{P}, \mathrm{As}$ generally assumed to be closely associated with these precipitates. $^{23}$ Organic carbon association with natural $\mathrm{Fe}$ oxyhydroxides is also common, with $\mathrm{C}$ : $\mathrm{Fe}$ ratios of 0.3 for ferrihydrite-rich flocs in groundwater at the Rifle site, ${ }^{24}$ and higher ratios, between 0.2 and 12 for soils, ${ }^{16,25}$ between $\sim 2$ and 5 for lacustrine $\mathrm{Fe}$ oxyhydroxides, ${ }^{26}$ and between 0.2 and 10 for freshwater, estuarine and marine sediments. ${ }^{27}$ Although it is difficult to confirm the exact origin of the (in)organic species, and crystalline phases or additional poorly crystalline phases may partially or completely dissolve during chemical extraction, it is also well-known that poorly crystalline Fe oxyhydroxides are highly reactive toward various ions and organic molecules. For the purpose of this work, we assume that a large fraction of the major organic and inorganic impurities released by the hydroxylamine hydrochloride extraction (e.g., organic matter, $\mathrm{Si}$ ) are associated with ferrihydrite in the Rifle sediment, either by means of incorporation or adsorption/surface precipitation.

The association of inorganic impurities and natural organic matter with natural ferrihydrite is frequent, has been observed in a variety of environments, ${ }^{5,22 b}$ and is known to impact ferrihydrite properties, such as particle size, crystallinity, aggregation, particle surface composition, and overall chemical reactivity. There is evidence indicating that the presence of inorganic impurities, e.g. $\mathrm{Al}^{28}$ phosphate $^{29}$ and silica, ${ }^{30}$ and coprecipitation with organic compounds ${ }^{31}$ can retard $\mathrm{Fe}(\mathrm{II})$ induced transformations to more crystalline $\mathrm{Fe}$ oxyhydroxides.

X-ray Diffraction of the Sediment. X-ray diffraction data for the unreacted and reacted Rifle sediment (Figure 1A) indicate the presence of abundant crystalline phases, although none that are dominated by Fe. We identified several minerals, namely quartz, feldspar, Illite, as well as calcite. The background of all diffraction patterns shows the presence of a diffuse scattering component, defined by broad features centered at approximately 22 and 38 degrees, which correspond to the ferrihydrite $d$-spacings at $\sim 2.5$ and $\sim 1.5 \AA$, respectively (Figure 1B). Although weak, these features are present consistently in all four samples, even in the 3,10, and $30 \mathrm{mM} \mathrm{Fe}(\mathrm{II})$-reacted samples (only data for the unreacted sediment and the $30 \mathrm{mM}$ $\mathrm{Fe}(\mathrm{II})$-reacted sample are shown in Figure 1B).

Overall, the sample series appears rather heterogeneous in terms of crystalline mineral phases; minerals such as Illite, for
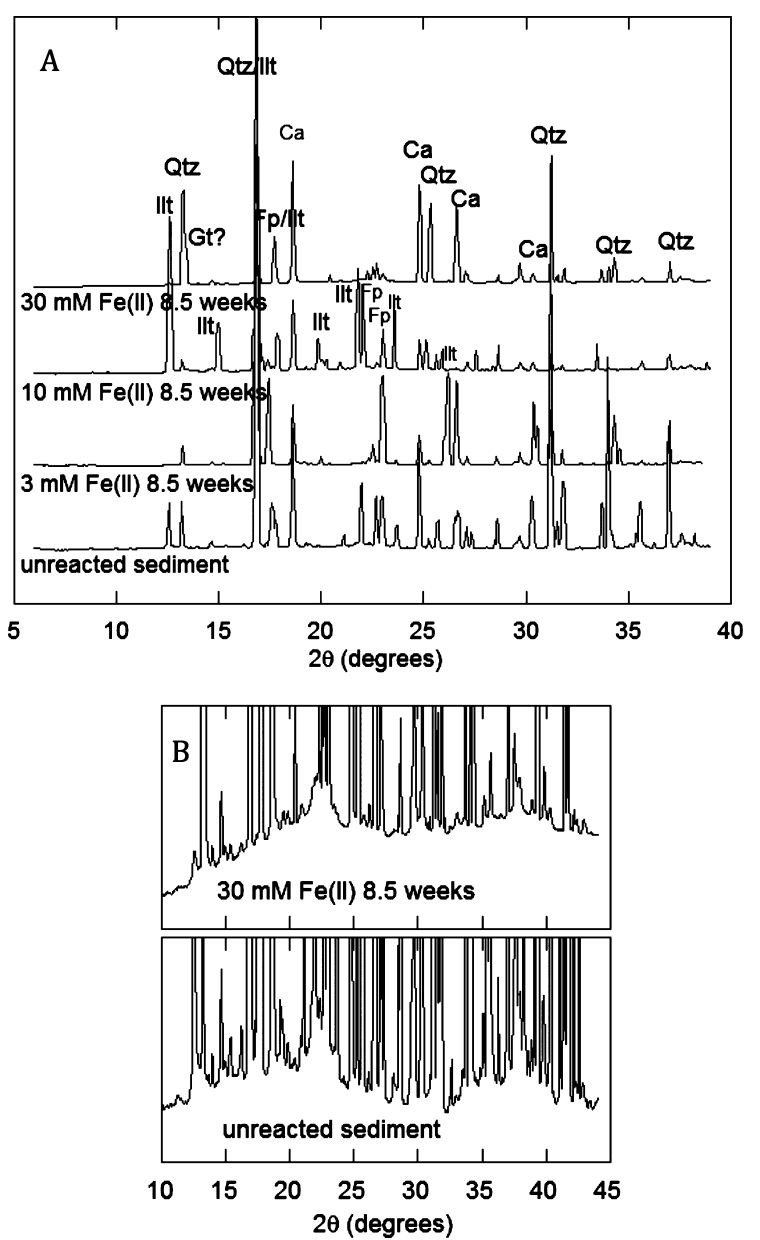

Figure 1. (A) XRD data $(\lambda=0.9762 \AA)$ for unreacted sediment and for sediment that has been reacted with 3,10 , and $30 \mathrm{mM} \mathrm{Fe}$ (II) for 8.5 weeks; crystalline phases identified are quartz (Qtz), calcite (Ca), feldspar (Fsp) and Illite (Ilt); goethite (Gt) may be present in the sample reacted with $30 \mathrm{mM}$ Fe(II). (B) Diffuse scattering component for selected samples (unreacted sediment and $30 \mathrm{mM} \mathrm{Fe}$ (II) reacted sediment). The broad features centered at $\sim 22$ and 38 degrees are assigned to ferrihydrite.

example, were identified only in the unreacted sample and in the $10 \mathrm{mM} \mathrm{Fe}$ (II) reacted sample. This may be due to both sample complexity and heterogeneity, combined with the limitations of $\mu \mathrm{XRD}$ measurements using a $0.1 \mathrm{~mm} \mathrm{X}$-ray beam. In addition, we did not observe the formation of more crystalline $\mathrm{Fe}$ oxyhydroxide minerals upon reaction with $\mathrm{Fe}(\mathrm{II})$. We were particularly interested in identifying reductive transformation products along the sample series, namely an increase in goethite, lepidocrocite, magnetite, etc. However, ferrihydrite predominates throughout the series of XRD spectra as the major $\mathrm{Fe}$ oxyhydroxide phase, and we found only one minor indication for the presence of goethite in the sample reacted with $30 \mathrm{mM} \mathrm{Fe}$ (II) for 8.5 weeks (although XRD cannot definitely rule out other nanoparticulate or amorphous Fe phases). This weak feature corresponds to the strongest goethite reflection, which occurs at $\sim 13.4$ degrees. No other peaks typical for goethite could be identified in this diffractogram possibly due to a very low goethite content, and although it is possible for goethite to form as a result of the interaction of ferrihydrite with Fe(II), we cannot be absolutely certain of its presence based only on one Bragg peak. 
Fe K-Edge XANES and EXAFS. Fe K-edge XANES spectra (Figure 2) for the unreacted sediment and $\mathrm{Fe}$ (II)-reacted solids

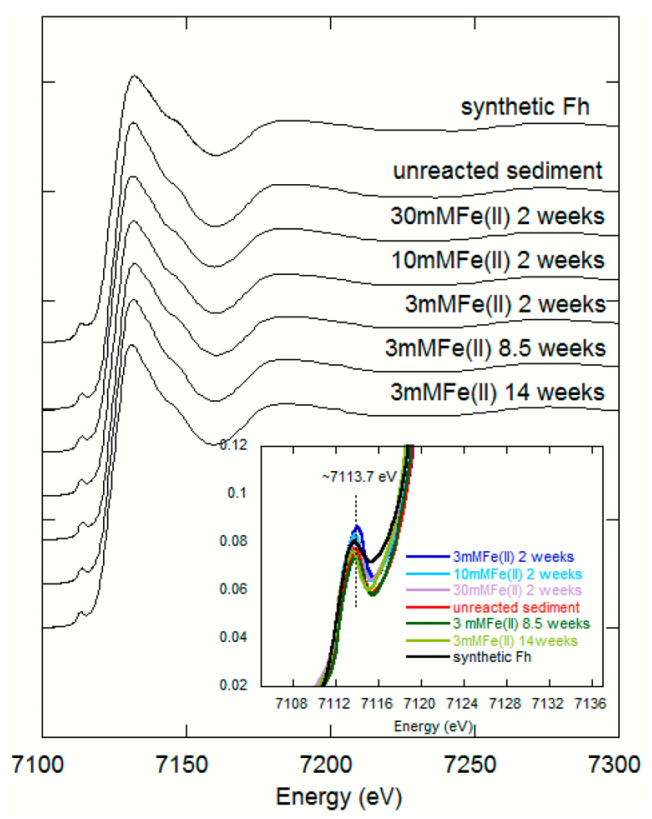

Figure 2. Fe K-edge XANES for unreacted and $\mathrm{Fe}(\mathrm{II})$-reacted sediment for 2, 8.5, and 14 weeks; inset illustrates pre-edge feature situated at an energy of $\sim 7113.7 \mathrm{eV}$; the $\mathrm{Fe}$ K-edge XANES for synthetic ferrihydrite is shown for comparison.

(3, 10, and $30 \mathrm{mM} \mathrm{Fe}(\mathrm{II})$ for 2 weeks; $3 \mathrm{mM}$ Fe for 8.5 weeks; $3 \mathrm{mM} \mathrm{Fe}$ (II) for 14 weeks) appear identical despite significant differences in the amount of $\mathrm{Fe}$ (II) reacted with the sediment ( 3 to $30 \mathrm{mM} \mathrm{Fe}(\mathrm{II})$ ) and increasing reaction times (from 2 to 14 weeks). The spectra shown in Figure 2 have equivalent edge and pre-edge profiles, that is, there are no shoulders, broadening, or shifts in energy in the edge or pre-edge regions for the $\mathrm{Fe}(\mathrm{II})$-reacted samples.

The position and intensity of the pre-edge feature is particularly sensitive to Fe oxidation state and coordination, ${ }^{32}$ and has been used to evaluate the chemistry of $\mathrm{Fe}$ in several environments, in sediments, groundwater and surface precipitates, soils, weathering products and glasses. Pre-edges are related to $1 \mathrm{~s}-3 \mathrm{~d}$ and $1 \mathrm{~s}-4 \mathrm{p}$ metal electronic transitions, and shift to higher energy with increasing oxidation state. For Fe(II)bearing phases, the centroid position of the pre-edge feature is situated at approximately $7112.1 \mathrm{eV}$, whereas its position shifts toward $\sim 7113.7 \mathrm{eV}$ for $\mathrm{Fe}(\mathrm{III})$. The pre-edge also exhibits variable and distinctive intensities that are related to coordination environment. For example, in the case of Fe(III) compounds, the highest pre-edge intensity has been linked to the presence of noncentrosymmetric geometry, or tetrahedral $\mathrm{Fe}^{3+}$ coordination. The position of the pre-edge feature for the unreacted and $\mathrm{Fe}$ (II)-reacted samples of this study is at an energy of $7113.7 \mathrm{eV}$, similar to synthetic ferrihydrite (see inset of Figure 2), and iron is expected to be primarily in ferric form. Furthermore, no systematic variations in pre-edge shape or intensity occur along the sample series, which suggests that the $\mathrm{Fe}$ coordination environment is not affected at these conditions as a result of reaction with $\mathrm{Fe}(\mathrm{II})$.

Fe K-edge EXAFS also indicate that no systematic changes occur in the EXAFS oscillation intensities or positions as a result of the amount of $\mathrm{Fe}$ (II) reacted with the sediment (3 to $30 \mathrm{mM}$ ), or with increasing reaction time. In order to evaluate in a more quantitative manner any changes in mineralogy as a result of this reaction, principal component analyses (PCA) and linear combination fits (LCF) were carried out on the Fe Kedge EXAFS spectra (Figure 3). PCA were carried out to constrain the minimum number of components, and to identify probable components needed to describe the data set. PCA results show that two principal components reproduce the experimental data set reasonably well (Figure 3A). Target
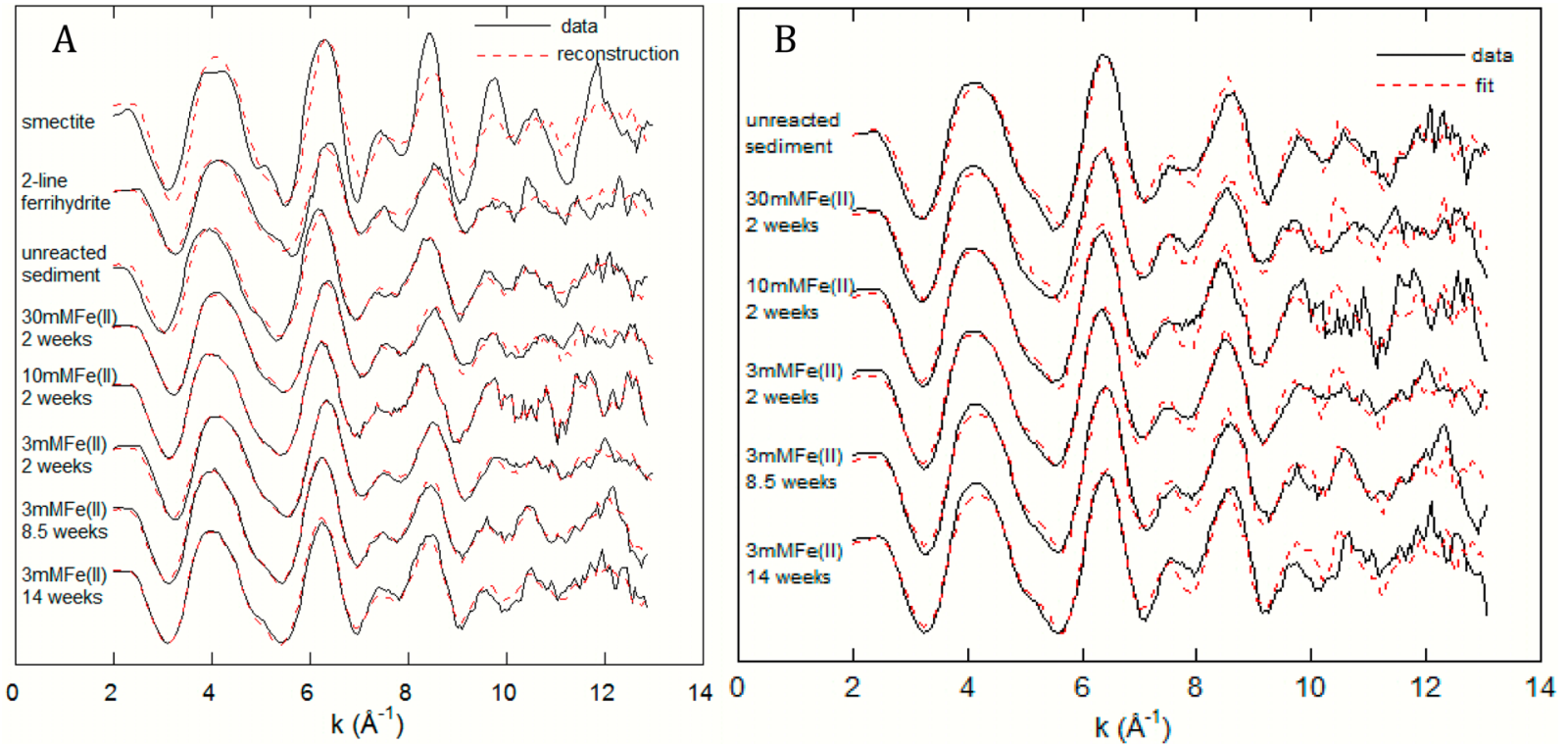

Figure 3. (A) Experimental and reconstructed Fe K-edge EXAFS for the unreacted and reacted sediment, and for reference smectite and ferrihydrite spectra. The fits obtained from spectrum reconstructions indicate that the Fe EXAFS of the Rifle sediment series can be described reasonably well by using only two principal components. Target transformations indicate a good fit to ferrihydrite and smectite, and these were identified as probable phases contained in the unreacted and Fe(II)-reacted Rifle sediment. (B) Fe K-edge EXAFS and linear combination fit results for unreacted and $\mathrm{Fe}(\mathrm{II})$-reacted sediment, using ferrihydrite and smectite as spectral components. LCF component proportions are given in Table 2. 
Table 2. Fe K-Edge EXAFS Linear Combination Fit Results for Unreacted and Fe(II)-Reacted Sediments

\begin{tabular}{|c|c|c|c|c|c|c|}
\hline LCF components & unreacted sediment & $3 \mathrm{mMFe}(\mathrm{II}) 2$ weeks & $10 \mathrm{mMFe}$ (II) 2 weeks & $30 \mathrm{mMFe}$ (II) 2 weeks & $3 \mathrm{mMFe}$ (II) 8.5 weeks & $3 \mathrm{mMFe}$ (II) 14 weeks \\
\hline ferrihydrite & $74 \%$ & $82 \%$ & $77 \%$ & $94 \%$ & $79 \%$ & $77 \%$ \\
\hline smectite & $26 \%$ & $19 \%$ & $23 \%$ & $6 \%$ & $21 \%$ & $23 \%$ \\
\hline Red. Chi-Sq: & 0.25 & 0.18 & 0.42 & 0.28 & 0.38 & 0.41 \\
\hline
\end{tabular}

transformations were used to identify possible model compounds from a set of reference spectra, which included ferrihydrite, smectite, goethite, hematite, magnetite, green rust, siderite, biotite, pyroxene, and amphibole. Two model compounds were found to yield satisfactory fits according to target transformations, namely ferrihydrite and to a lesser extent, smectite (see Figure 3A for target transform results). Ideally, an Fe-bearing Illite standard would have been suitable for these analyses, since this phase was identified by means of $\mathrm{XRD}$ in the sediment. Here we use a ferrous smectite as a model compound, which approximates well the Fe K-edge EXAFS spectrum of Fe-bearing Illite, when compared to literature results. ${ }^{33}$

LCFs were carried out on the Fe EXAFS and yielded best fits for all samples when using ferrihydrite and smectite as $\mathrm{Fe}$ spectral components (Figure 3B). The proportion of ferrihydrite obtained by LCF varies from 74 to $94 \%$ of the Fe EXAFS signal for the series of experimental spectra, and the proportion of ferrihydrite is not correlated with $\mathrm{Fe}(\mathrm{II})$ amount or reaction time (Table 2). In the case of the $\mathrm{Fe}(\mathrm{II})$-reacted samples, fits were carried out initially using only ferrihydrite and smectite, but additional $\mathrm{Fe}(\mathrm{II}) / \mathrm{Fe}(\mathrm{III})$ oxyhydroxide components, for example, goethite, lepidocrocite, hematite, carbonate/sulfate green rust, siderite and magnetite were included in the fit subsequently to test any possible improvement in the fit quality. No significant improvement was obtained (changes in reduced chi sq. $<0.04$ ) by means of this procedure.

Some visible misfits occur at $k$ values between 9 and $13 \AA^{-1}$ for all samples except for the unreacted sample and $3 \mathrm{mM}$ $\mathrm{Fe}(\mathrm{II}) 8.5$ weeks (Figure 3). These misfits are not systematic, i.e. there are no correlations with $\mathrm{Fe}(\mathrm{II})$ reaction amount/time. Overall, PCA results combined with linear combination fits and the qualitative analysis of the Fe XANES pre-edge, and the chemical extraction results suggest that ferrihydrite is the major $\mathrm{Fe}(\mathrm{III})$-bearing phase in the Rifle sediment, and that its reaction with $3 \mathrm{mM} \mathrm{Fe}$ (II) for up to 14 weeks and $30 \mathrm{mM}$ $\mathrm{Fe}$ (II) for up to 2 weeks did not promote reductive transformation to more crystalline Fe oxyhydroxides. However, XRD results hint that small amounts of goethite may have formed after 8.5 weeks of exposure to $30 \mathrm{mM} \mathrm{Fe}$ (II).

The ferrihydrite fraction of the unreacted sediment contains appreciable levels of cations including $\mathrm{Al}, \mathrm{Si}, \mathrm{Mn}$, and organic matter (Table 1). The impact of substitution and/or adsorption, as well as $\mathrm{OM}$ association on $\mathrm{Fe}(\mathrm{II})$-promoted transformation of ferrihydrite to more crystalline phases including goethite, lepidocrocite, and magnetite has been evaluated in several studies. ${ }^{28}$ Masue et al. ${ }^{28 \mathrm{c}}$ found that $\mathrm{Al}$ substituted into the structure of ferrihydrite, along with As adsorbed on the surface completely inhibited transformation to other phases with $\mathrm{Fe}(\mathrm{II})$ levels of $1.7 \mathrm{mM}$, whereas Hansel ${ }^{28 a}$ observed that $\mathrm{Al}$ adsorbed to the surface of ferrihydrite had a greater impact than substitution on impeding transformation to other phases. Additional studies have shown that phosphate ${ }^{29}$ as well as silica ${ }^{31}$ also impact variably transformation rates and products. Finally, the reductive transformation of synthetic ferrihydrite-humic acid coprecipitates also appeared to be affected by the amount of organic $\mathrm{C}$, with slower reduction rates at $\mathrm{C} / \mathrm{Fe}$ ratios $\leq 0.8$ and higher rates at $\mathrm{C} / \mathrm{Fe}$ ratios $\geq 1.8$. ${ }^{33}$ We suggest that the amount and types of impurities contained in the Rifle ferrihydrite (Table 1) play a central role in the observed inhibition, or delay of $\mathrm{Fe}$ (II)-mediated reductive transformation.

Uranium(VI) Adsorption onto Sediment and Ferrihydrite. Figure 4 compares the U(VI) adsorptive capacity of the

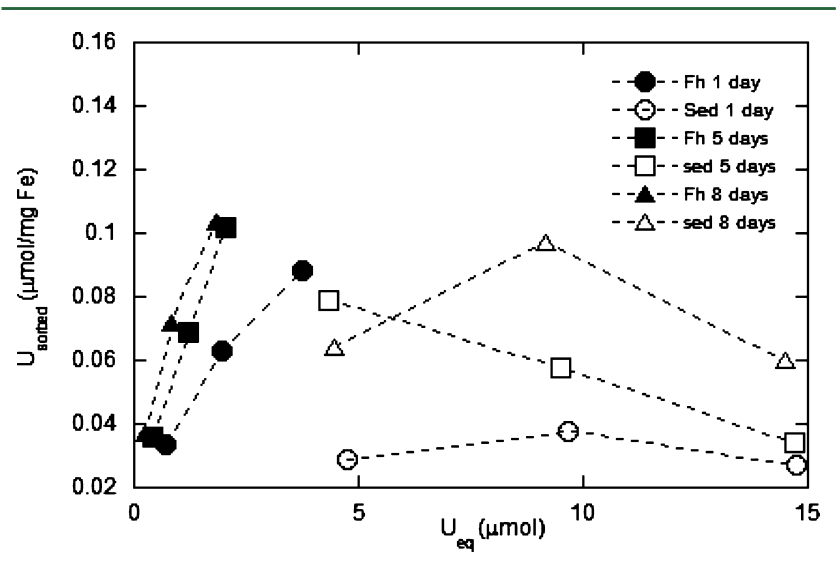

Figure 4. Uranium adsorption curves comparing synthetic ferrihydrite and unreacted sediment on a per mg Fe basis.

unreacted Rifle sediment with synthetic ferrihydrite. The results indicate that on a per $\mathrm{Fe}$ basis the synthetic ferrihydrite has a significantly larger capacity to adsorb U(VI) than the unreacted Rifle sediment (Figure 4). This may be attributed to a combination of higher reactive Fe surface area as compared to the sediment, and/or a lower affinity of surface sites on the sediment toward $\mathrm{U}(\mathrm{VI})$. When results are normalized for both $\mathrm{Fe}$ content and surface area there is still significantly more $(>10 \mathrm{x}) \mathrm{U}(\mathrm{VI})$ associated with the ferrihydrite than with the Rifle sediment (i.e., per mol Fe and per $\mathrm{m}^{2}$ ), suggesting that the primary reason for differences in adsorption behavior is a discrepancy in site availability for U(VI). In this case, we hypothesize that a portion of surface sites on the natural sediment are occupied by other ions (e.g., $\mathrm{Si}$ ), or that particle surfaces exhibit surface precipitates/polymers (e.g., Si polymers) and/or organic coatings. Several studies on synthetic and natural Si-bearing ferrihydrite indicate that $\mathrm{Si}$ is likely not incorporated in the ferrihydrite structure, but rather resides at particle surfaces, ${ }^{34}$ and this can have an impact on metal(loid) adsorption capacity and surface speciation. Additionally, the presence of organic molecules at mineral surfaces has also been shown to significantly impact U(VI) adsorption and desorption reactions; ${ }^{35}$ a potential explanation for the observation of decreased uranium adsorption on the Rifle sediment.

Sediment Interaction with $\mathrm{U}(\mathrm{VI})$ and Fe(II). Results from experiments in which the Rifle sediment was incubated with both $\mathrm{U}(\mathrm{VI})$ and $\mathrm{Fe}(\mathrm{II})$ concurrently suggest that no major mineralogical transformation occurred during the course of the experiment. Sediments did not appear to change dramatically in 


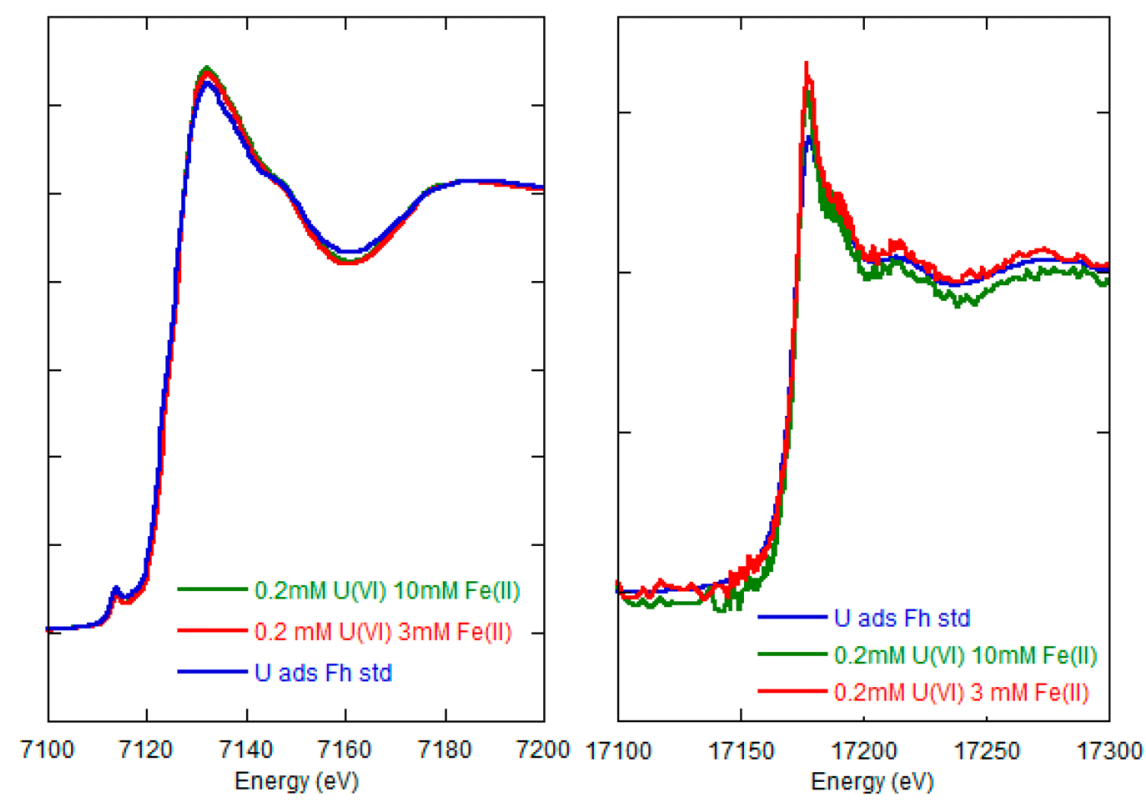

Figure 5. Iron K-edge (A) and uranium L-edge (B) XANES results for unreacted sediment reacted with $0.2 \mathrm{mM} \mathrm{U}(\mathrm{VI})$ and 3 or $10 \mathrm{mM}$ Fe(II) compared to synthetic ferrihydrite (A) and $U$ adsorbed on the surface of ferrihydrite (B); local coordination environment of $U$ and Fe in reacted sediment is similar to standards in both cases.

color as we observed in similar previous studies with synthetic ferrihydrite where an appreciable fraction of ferrihydrite transformed to magnetite and goethite with $\mathrm{U}$ incorporated into the mineral matrix. ${ }^{15 \mathrm{~b}, 36}$ Figure 5 illustrates that within the estimated $<5-10 \%$ error of XANES analysis, ${ }^{37}$ the oxidation state and local coordination chemistry of $\mathrm{Fe}$ and $\mathrm{U}$ are comparable to $\mathrm{Fe}$ (III) in ferrihydrite (in the case of $\mathrm{Fe}$ ) and to $\mathrm{U}(\mathrm{VI})$ adsorbed on the surface of synthetic ferrihydrite in the case of $U$ (the minor differences between the Fe spectra in Figure 5 are consistent with classic "overabsorption" or "selfabsorption" distortions ${ }^{38}$ ). These results further support an increased stabilization of the ferrihydrite in the Rifle sediment, and also indicate that $U$ binds preferentially to Fe reactive sites, in spite of their lower availability at the ferrihydrite surface (Figure 4).

These results suggest that appreciable levels of Fe(II) are not incorporated into the sediment, nor is there significant $\mathrm{Fe}$ (II) associated with the solid surface. This is consistent with results from the $\mathrm{Fe}(\mathrm{II})$ incubation experiments (described above) where no transformation of the Rifle sediment to more crystalline $\mathrm{Fe}(\mathrm{III}) / \mathrm{Fe}(\mathrm{II})$ minerals was detected. This result is perhaps unsurprising given that adsorption of $\mathrm{Fe}$ (II) to the surface of ferrihydrite (or similar material) is a required step in $\mathrm{Fe}(\mathrm{II})$ - promoted mineral transformation, ${ }^{39}$ a precursor for $\mathrm{U}$ incorporation into the solid. ${ }^{15 \mathrm{~b}, \mathrm{~d}}$ Additionally, Massey et al. recently observed that $\mathrm{Al}$ substituted into synthetic ferrihydrite at levels as low as $1 \mathrm{~mol} \%$ decreased incorporation of $\mathrm{U}$ into $\mathrm{Fe}$ mineral structure during $\mathrm{Fe}(\mathrm{II})$ promoted transformation by $\sim 20 \%$ (Massey personal communication).

Implications. Comparing the reactivity of synthetic materials to field materials and elucidating the impact of mineral impurities, both within mineral structure and associated with surfaces, on potential transformation of poorly crystalline $\mathrm{Fe}$ (III) hydroxides is critical to accurately predicting both iron mineral transformation pathways and the fate of metals and organic matter associated with these minerals. Our results show dramatic differences in the rates and extent of transformation of Fe minerals and associated $U$ with natural field materials as compared to those reported for laboratory systems. The materials used here are likely to be representative of a large class of naturally occurring ferrihydrite-like materials that form from complex natural waters at abrupt redox boundaries. Therefore, the decreased reactivity of the materials examined herein should be considered when predicting the fate of iron minerals and their associated species, such as $U$ and organic matter. Dissolution of these minerals could result in the release of contaminant metals and oxyanions including $U$, while stability or persistence of these impure or substituted oxides could foreseeably result in attenuation of metal and metalloid pollutants through continued association with a more recalcitrant solid phase. While $\mathrm{Fe}$ (III) associated with these coprecipitated oxyhydroxides may be bioavailable for respiration by metal reducing microorganisms, resulting in elevated $\mathrm{Fe}$ (II) levels, the transformation of these materials is expected to be delayed (as compared to predictions based on synthetic ferrihydrite) as a result of exposure to $\mathrm{Fe}(\mathrm{II})$. Results shown here could help to explain the observed uranium concentrations present in these solids that appears to be both oxidized and stable (immobile) and suggests a potential means for natural uranium attenuation that is stable under both oxic and anoxic conditions.

\section{ASSOCIATED CONTENT}

\section{S Supporting Information}

The Supporting Information is available free of charge on the ACS Publications website at DOI: 10.1021/acs.est.5b02645.

Details of FE SEM imaging, surface area measurements and XAS data collection (PDF)

\section{AUTHOR INFORMATION}

\section{Corresponding Author}

*Phone: 510-486-7118; e-mail: psnico@lbl.gov.

\section{Notes}

The authors declare no competing financial interest. 


\section{ACKNOWLEDGMENTS}

We thank Aaron Slowey and Michael Massey for assistance with XAS data collection. This research was funded by the U.S. Department of Energy (DOE), Office of Science, Office of Biological and Environmental Research under contracts DEFG02-07ER-6436 (Montana State University) and DE-AC0205CH11231 (Lawrence Berkeley National Laboratory; operated by the University of California) and is partially based upon work supported through the Lawrence Berkeley National Laboratory's Sustainable Systems Scientific Focus Area.

\section{REFERENCES}

(1) (a) (GAO), U. S. G. A. O., Nuclear Waste Problems Associated with DOE's Inactive Waste Sites, GAO/RCED-88-169 1988a; (b) (GAO)., U. S. G. A. O. Nuclear Waste, Supplemental Information on Problems at DOE's Inactive Waste Sites; U.S. Government Accounting Office: Washington, DC, 1988b; pp GAO/RCED-88-229FS.

(2) Smythe, C.; Bierley, D.; Bradshaw, M. US regulatory framework for long-term management of uranium mill tailings. Journal of the Mine Ventilation Society of South Africa 1995, 48 (10), 246-253.

(3) Abdelouas, A.; Lutze, W.; Nuttall, E. Chemical reactions of uranium in ground water at a mill tailings site. J. Contam. Hydrol. 1998, 34 (4), 343-361.

(4) Processing Sites and Disposal Site; U.S. Department of Energy: Rifle, CO, 2013.

(5) Thompson, A.; Chadwick, O. A.; Rancourt, D. G.; Chorover, J. Iron-oxide crystallinity increases during soil redox oscillations. Geochim. Cosmochim. Acta 2006, 70 (7), 1710-1727.

(6) Rancourt, D. G.; Thibault, P. J.; Mavrocordatos, D.; Lamarche, G. Hydrous ferric oxide precipitation in the presence of nonmetabolizing bacteria: Constraints on the mechanism of a biotic effect. Geochim. Cosmochim. Acta 2005, 69 (3), 553-577.

(7) Liang, L. Y.; McCarthy, J. F.; Jolley, L. W.; McNabb, J. A.; Mehlhorn, T. L. Iron dynamics - transformation of $\mathrm{Fe}(\mathrm{II}) / \mathrm{Fe}(\mathrm{III})$ during injection of natural organic-matter in a sandy aquifer. Geochim. Cosmochim. Acta 1993, 57 (9), 1987-1999.

(8) Pullin, M. J.; Cabaniss, S. E. The effects of pH, ionic strength, and iron-fulvic acid interactions on the kinetics of nonphotochemical iron transformations. I. Iron(II) oxidation and iron(III) colloid formation. Geochim. Cosmochim. Acta 2003, 67 (21), 4067-4077.

(9) Brown Jr., G. E.; Trainor, T. P.; Chaka, A. M., Geochemistry of mineral surfaces and factors affecting their chemical reactivity. In Chemical Bonding at Surfaces and Interfaces; Nilsson, A., Patterson, L. G. M., Norskov, J., Ed.; Elsevier: New York, 2007; pp 457-509.

(10) Read, D. Geochemical Modeling of Uranium Redistribution in the Osamu Utsumi Mine, Pocos-De-Caldas. J. Geochem. Explor. 1992, $45(1-3), 503-520$.

(11) Stubbs, J. E.; Elbert, D. C.; Veblen, D. R.; Zhu, C. Electron microbeam investigation of uranium-contaminated soils from Oak Ridge, TN, USA. Environ. Sci. Technol. 2006, 40 (7), 2108-2113.

(12) Campbell, K. M.; Kukkadapu, R. K.; Qafoku, N. P.; Peacock, A. D.; Lesher, E.; Williams, K. H.; Bargar, J. R.; Wilkins, M. J.; Figueroa, L.; Ranville, J.; Davis, J. A.; Long, P. E. Geochemical, mineralogical and microbiological characteristics of sediment from a naturally reduced zone in a uranium-contaminated aquifer. Appl. Geochem. 2012, 27 (8), $1499-1511$.

(13) (a) Gomez, P.; Garralon, A.; Buil, B.; Turrero, M. J.; Sanchez, L.; de la Cruz, B. Modeling of geochemical processes related to uranium mobilization in the groundwater of a uranium mine. Sci. Total Environ. 2006, 366 (1), 295-309. (b) Reed, D. T.; Pepper, S. E.; Richmann, M. K.; Smith, G.; Deo, R.; Rittmann, B. E. Subsurface biomediated reduction of higher-valent uranium and plutonium. J. Alloys Compd. 2007, 444-445, 376-82.

(14) (a) Murakami, T.; Ohnuki, T.; Isobe, H.; Sato, T. Mobility of uranium during weathering. Am. Mineral. 1997, 82 (9-10), 888-899. (b) Gu, B. H.; Brooks, S. C.; Roh, Y.; Jardine, P. M. Geochemical reactions and dynamics during titration of a contaminated ground- water with high uranium, aluminum, and calcium. Geochim. Cosmochim. Acta 2003, 67 (15), 2749-2761. (c) Payne, T. E.; Airey, P. L. Radionuclide migration at the Koongarra uranium deposit, Northern Australia - Lessons from the Alligator Rivers analogue project. Physics and Chemistry of the Earth 2006, 31 (10-14), 572586.

(15) (a) Duff, M. C.; Coughlin, J. U.; Hunter, D. B. Uranium coprecipitation with iron oxide minerals. Geochim. Cosmochim. Acta 2002, 66 (20), 3533-3547. (b) Nico, P. S.; Stewart, B. D.; Fendorf, S. Incorporation of Oxidized Uranium into $\mathrm{Fe}$ (Hydr)oxides during $\mathrm{Fe}(\mathrm{II})$ Catalyzed Remineralization. Environ. Sci. Technol. 2009, 43 (19), 7391-7396. (c) Boland, D. D.; Collins, R. N.; Payne, T. E.; Waite, T. D. Effect of Amorphous Fe(III) Oxide Transformation on the Fe(II)-Mediated Reduction of U(VI). Environ. Sci. Technol. 2011, 45 (4), 1327-1333. (d) Boland, D. B.; Collins, R. N.; Glover, C. J.; Payne, T. E.; Waite, D. T. Reduction of U(VI) by Fe(II) during the $\mathrm{Fe}(\mathrm{II})$-accelerated transformation of ferrihydrite. Environ. Sci. Technol. 2014, 48 (16), 9086-9093.

(16) Wagai, R.; Mayer, L. M. Sorptive stabilization of organic matter in soils by hydrous iron oxides. Geochim. Cosmochim. Acta 2007, 71 (1), 25-35.

(17) Chao, T. T.; Zhou, L. Extraction techniques for selective dissolution of amorphous iron-oxides from soils and sediments. Soil Science Society of America Journal 1983, 47 (2), 225-232.

(18) Brooks, S. C.; Taylor, D. L.; Jardine, P. M. Reactive transport of EDTA-complexed cobalt in the presence of ferrihydrite. Geochim. Cosmochim. Acta 1996, 60 (11), 1899-1908.

(19) Hammersley, A. P. Fit2D V9.129 Reference Manual V. 3.1; ESFR Internal Report ESRF98HA01; T. European Synchrotron Radiation Facility: Grenoble, France, 1998; p 306.

(20) Webb, S. M. SIXPack: a graphical user interface for XAS analysis using IFEFFIT. Phys. Scr. 2005, 2005 (T115), 4.

(21) Zachara, J. M.; Long, P. E.; Bargar, J. R.; Davis, J. A.; Fox, P.; Fredrickson, J. K.; Freshley, M. D.; Konopka, A.; Lui, C.; McKinley, J. P.; Rockhold, M.; Williams, K. H.; Yabusaki, S. B. Persistence of uranium groundwater plumes: Contrasting mechanisms at two DOE sites in the groundwater-river interaction zone. J. Contam. Hydrol. 2013, 147, 45-72.

(22) (a) De Endredy, A. S. Estimation of free iron oxides in soils and clays by a photolytic method. Clay Miner. 1963, 5, 209-217. (b) Jambor, J. L.; Dutrizac, J. E. Occurrence and constitution of natural and synthetic ferrihydrite, a widespread iron oxyhydroxide. Chem. Rev. 1998, 98 (7), 2549-2585.

(23) (a) Carlson, L.; Bigham, J. M.; Schwertmann, U.; Kyek, A.; Wagner, F. Scavenging of As from acid mine drainage by schwertmannite and ferrihydrite: a comparison with synthetic analogues. Environ. Sci. Technol. 2002, 36 (8), 1712-1719. (b) Kumpulainen, S.; Carlson, L.; Raisanen, M.-L. Seasonl variations of ochreous precipitates in mine effluents in Finland. Appl. Geochem. 2007, 22 (4), 760-777.

(24) Cismasu, A. C.; Williams, K. H.; Nico, P. S., Selective degradation of mineral-bound organic matter under fluctuating redox conditions Environ. Sci. Technol. in review.

(25) (a) Kleber, M.; Mikutta, R; Torn, M. S.; Jahn, R. Poorly crystalline mineral phases protect organic matter in acid subsoil horizons. Eur. J. Soil Sci. 2005, 56 (6), 717-725. (b) Thompson, A.; Rancourt, D. G.; Chadwick, O. A.; Chorover, J. Iron solid-phase differentiation along a redox gradient in basaltic soils. Geochim. Cosmochim. Acta 2011, 75 (1), 119-133.

(26) Fortin, D.; Leppard, G. G.; Tessier, A. Characteristics of lacustrine diagenetic iron oxyhydroxides. Geochim. Cosmochim. Acta 1993, 57 (18), 4391-4404.

(27) Lalonde, K.; Mucci, A.; Ouellet, A.; Gelinas, Y., Preservation of organic matter in sediments promoted by iron. Nature 2012, 483 (7388), 198-200.10.1038/nature10855

(28) (a) Hansel, C. M.; Learman, D. R.; Lentini, C. J.; Ekstrom, E. B. Effect of adsorbed and substituted $\mathrm{Al}$ on $\mathrm{Fe}(\mathrm{II})$-induced mineralization pathways of ferrihydrite. Geochim. Cosmochim. Acta 2011, 75 (16), 4653-4666. (b) Ekstrom, E. B.; Learman, D. R.; Madden, A. S.; 
Hansel, C. M. Contrasting effects of Al substitution on microbial reduction of $\mathrm{Fe}(\mathrm{III})$ (hydr)oxides. Geochim. Cosmochim. Acta 2010, 74 (24), 7086-7099. (c) Masue-Slowey, Y.; Loeppert, R. H.; Fendorf, S. Alteration of ferrihydrite reductive dissolution and transformation by adsorbed As and structural Al: Implications for As retention. Geochim. Cosmochim. Acta 2011, 75 (3), 870-886.

(29) Borch, T.; Masue, Y.; Kukkadapu, R. K.; Fendorf, S. Phosphate imposed limitations on biological reduction and alteration of ferrihydrite. Environ. Sci. Technol. 2007, 41 (1), 166-172.

(30) Jones, A. M.; Collins, R. N.; Rose, J.; Waite, T. D. The effect of silica and natural organic matter on the $\mathrm{Fe}(\mathrm{II})$-catalysed transformation and reactivity of $\mathrm{Fe}(\mathrm{III})$ minerals. Geochim. Cosmochim. Acta 2009, 73 (15), 4409-4422.

(31) (a) Henneberry, Y. K.; Kraus, T. E. C.; Nico, P. S.; Horwath, W. R., Structural stability of coprecipitated natural organic matter and ferric iron under reducing conditions. Org. Geochem. 2012, 48, 81-89 10.1016/j.orggeochem.2012.04.005. (b) Shimizu, M.; Zhou, J. H.; Schroder, C.; Obst, M.; Kappler, A.; Borch, T., Dissimilatory Reduction and Transformation of Ferrihydrite-Humic Acid Coprecipitates. Environ. Sci. Technol. 2013, 47 (23), 13375-13384 10.1021/ es402812j.

(32) Wilke, M.; Farges, F.; Petit, P. E.; Brown, G. E.; Martin, F. Oxidation state and coordination of $\mathrm{Fe}$ in minerals: An FeK-XANES spectroscopic study. Am. Mineral. 2001, 86 (5-6), 714-730.

(33) Takahashi, Y.; Higashi, M.; Furukawa, T.; Mitsunobu, S. Change of iron species and iron solubility in Asian dust during the long-range transport from western China to Japan. Atmos. Chem. Phys. 2011, 11 (21), 11237-11252.

(34) (a) Cismasu, A. C.; Levard, C.; Michel, F. M.; Brown, G. E., Properties of impurity-bearing ferrihydrite II: Insights into the surface structure and composition of pure, $\mathrm{Al}$ - and Si-bearing ferrihydrite from $\mathrm{Zn}(\mathrm{II})$ sorption experiments and $\mathrm{Zn}$ K-edge X-ray absorption spectroscopy. Geochim. Cosmochim. Acta 2013, 119, 46-60 10.1016/ j.gca.2013.05.040. (b) Dyer, L. G.; Chapman, K. W.; English, P.; Saunders, M.; Richmond, W. R., Insights into the crystal and aggregate structure of Fe3+ oxide/silica co-precipitates. Am. Mineral. 2012, 97 (1), 63-69 10.2138/am.2011.3874.

(35) Yang, Y.; Saiers, J. E.; Barnett, M. O. Impact of Interactions between Natural Organic Matter and Metal Oxides on the Desorption Kinetics of Uranium from Heterogeneous Colloidal Suspensions. Environ. Sci. Technol. 2013, 47 (6), 2661-2669.

(36) Stewart, B. D.; Nico, P. S.; Fendorf, S. Stability of Uranium Incorporated into $\mathrm{Fe}$ (Hydr)oxides under Fluctuating Redox Conditions. Environ. Sci. Technol. 2009, 43 (13), 4922-4927.

(37) (a) Wu, W.-M.; Carley, J.; Luo, J.; Ginder-Vogel, M. A.; Cardenas, E.; Leigh, M. B.; Hwang, C.; Kelly, S. D.; Ruan, C.; Wu, L.; Van Nostrand, J.; Gentry, T.; Lowe, K.; Mehlhorn, T.; Carroll, S.; Luo, W.; Fields, M. W.; Gu, B.; Watson, D.; Kemner, K. M.; Marsh, T.; Tiedje, J.; Zhou, J.; Fendorf, S.; Kitanidis, P. K.; Jardine, P. M.; Criddle, C. S. In situ bioreduction of uranium (VI) to submicromolar levels and reoxidation by dissolved oxygen. Environ. Sci. Technol. 2007, 41 (16), 5716-5723. (b) Singer, D. M.; Zachara, J. M.; Brown, G. E., Jr. Uranium Speciation As a Function of Depth in Contaminated Hanford Sediments - A Micro-XRF, Micro-XRD, and Micro- And Bulk-XAFS Study. Environ. Sci. Technol. 2009, 43 (3), 630-636.

(38) Manceau, A.; Marcus, M. A.; Tamura, N., Quantitative speciation of heavy metals in soils and sediments by synchrotron $\mathrm{X}$ ray techniques. In Applications of 623 Synchrotron Radiation in LowTemperature Geochemistry and Environmental 624 Sciences; Fenter, P. A.; Rivers, M. L., Sturchio, N. C., Sutton, S. R., Eds.; 2002; Vol. 49, pp 341-428.

(39) (a) Hansel, C. M.; Fendorf, S.; Sutton, S.; Newville, M. Characterization of Fe plaque and associated metals on the roots of mine-waste impacted aquatic plants. Environ. Sci. Technol. 2001, 35 (19), 3863-3868. (b) Cornell, R. M.; Schwertmann, U. The Iron Oxides: Structure, Properties, Reactions, Occurences and Uses; WileyVCH, 2003. 